Global Conferences Series:

Sciences and Technology (GCSST), Volume,5, 2020

Seminar Nasional I Baristand Industri Padang (Semnas I BIPD)

DOI:https://doi.org/10.32698/GCS-SNIIBIPD3442

\title{
Performance test of wastewater treatment plant: anaerobic pond combination of honey comb biofilter and multi layer filtration
}

\section{Uji kinerja instalasi pengolahan air limbah cair: metode bak anaerob kombinasi media sarang tawon dan penyaring berlapis}

\author{
Masmulki Daniro Jyoti ${ }^{1}$, Karim Abdullah ${ }^{1}$, Dinar Maharani ${ }^{1}$, Eva ${ }^{1}$ \\ ${ }^{1}$ Balai Riset dan Standardisasi Industri Bandar Lampung, Indonesia \\ E-mail: daaniiroo@gmail.com
}

\begin{abstract}
The process in the laboratory produces waste that must be treated before releasing into the environment. One of the laboratory wastewater characteristics is high surfactant, COD and TSS content. This research will examine the performance of the anaerobic system of Wastewater Treatment Plants (IPAL) which uses a combined wasp nest with multi-layer filtration $(M L F)$ in treating laboratory wastewater. Wastewater flows into the wasp nest media and MLF then, samples are taken at the inlet point, wasp nest outlet and MLF outlet. The water at each point was then tested for $\mathrm{pH}$ value, ammonia content, turbidity, COD, TSS, Fatty Oil and Surfactant as MBAS on days 1, 3 and 5. The test results showed that the combination of wasp nests and MLF was able to reduce the turbidity value. amounted to $84.3 \%$, TSS $68.2 \%$, COD $68.33 \%$, Fatty Oil $63.46 \%$, MBAS $61.23 \%$ and ammonia 25\%. In addition, IPAL is able to restore the pH of the air to neutral.
\end{abstract}

Keywords: Wastewater Treatment Plant; Honey Comb; Multi Layer Filtration; Wastewater

\begin{abstract}
Abstrak: Proses pengujian pada laboratorium menghasilkan limbah cair yang harus diolah terlebih dahulu sebelum dibuang ke lingkungan. Salah satu karakteristik dari air limbah laboratorium adalah kandungan surfaktan, COD dan TSS yang tinggi. Pada penelitian ini akan dikaji kinerja Instalasi Pengolahan Air Limbah (IPAL) sistem anaerob yang menggunakan sarang tawon dikombinasikan dengan multi layer filtration (MLF) dalam mengolah air limbah laboratorium. Air limbah dialirkan ke dalam media sarang tawon dan MLF, lalu sampel diambil pada titik inlet, outlet sarang tawon dan outlet MLF. Air pada masing-masing titik selanjutnya diuji nilai $\mathrm{pH}$, kandungan ammonia, Kekeruhan, COD, TSS, Minyak Lemak dan Surfaktan sebagai MBAS pada hari ke-1, 3 dan 5. Hasil pengujian menunjukan bahwa kombinasi media sarang tawon dan MLF telah efektif untuk menurunkan nilai kekeruhan sebesar 84,3\%, TSS 68,2\%, COD 68,33\%, Minyak Lemak 63,46\% MBAS $61,23 \%$ dan ammonia sebesar 25\%. Selain itu, IPAL mampu mengembalikan $\mathrm{pH}$ air menjadi netral.
\end{abstract}

Kata kunci: IPAL; Sarang Tawon; Multi Layer Filtration; Limbah Cair

\section{PENDAHULUAN}

Pada proses pengujian yang dilakukan di Laboratorium penguji, dihasilkan tiga jenis limbah yaitu limbah padat, limbah berbahaya dan beracun (B3) dan limbah cair. Limbah B3 dihasilkan dari pengujian dengan menggunakan bahan kimia tertentu yang harus diolah dan disimpan secara khusus. Sedangkan limbah cair berasal dari pencucian peralatan gelas dan juga sisa sampel hasil pengujian yang dibuang melalui wastafel. Limbah cair dapat diolah secara mandiri oleh laboratorium pada suatu instalasi pengolahan air limbah (IPAL) hingga menghasilkan air yang sesuai baku mutu yang telah ditentukan. Proses pengolahan tergantung pada karakteristik limbah yang dihasilkan, sehingga desain IPAL harus disesuaikan dengan kondisi yang ada.

Copyright (C) 2020, the Authors. Published by Redwhite Press. 
Air yang banyak mengandung senyawa organik, deterjen, dan ammonia dapat diolah secara alami melalui reaksi dalam kondisi anaerob terlebih dahulu sebelum dilakukan proses lebih lanjut (Said, 2009). Salah satu teknik pengolahan air limbah yang telah banyak digunakan untuk air sisa buangan laboratorium adalah metode media tercelup, dimana proses pengolahan berdasarkan pada reaksi aerob-anaerob.

Beberapa penelitian yang telah dilakukan terkait menggunakan kombinasi biofilter anaerob dan aerob dengan media serat untuk mengolah limbah rumah tangga dengan waktu retensi antara 12 hingga 24 jam mampu menghilangkan atau menyisihkan kandungan pencemar yakni BOD, COD, deterjen (MBAS) dan Total padatan tersuspensi (TSS) dengan baik, yakni masing-masing efisiensi penghilangan BOD 73,24 94,92 \%, COD 65,80 - 90,76 \%, deterjen (MBAS) 56,80 - 88,51 \%, dan TSS 95,60 - 97.69 \% (Said, 2005).

Proses biofilter sarang tawon juga mampu mengolah limbah yang mengandung nitrat $\left(\mathrm{NO}_{3}\right)$, nitrit $\left(\mathrm{NO}_{2}\right)$, dan ammonia $\left(\mathrm{NH}_{3}\right)$, namun proses pengolahannya membutuhkan waktu yang relatif lama mencapai 6-7 hari dengan efektifitas penurunan kadar nitrit $\left(\mathrm{NO}_{2}\right)$ sebesar 97,23\%, kadar ammonia $\left(\mathrm{NH}_{3}\right)$ sebesar $85,80 \%$, kadar N-total sebesar 43,65\% (Sali et.al., 2018)

Media sarang tawon juga dapat digunakan untuk proses pengolahan limbah tahu dan tempe. Efisiensi penurunan nilai $\mathrm{BOD}_{5}$ pada reaktor yang memakai media biofilter berkisar 53,33 - 91,36\% dan nilai COD berkisar 61,15- 85,83\% dengan waktu tinggal berkisar $1-7$ hari. (Herlambang, 2001). Sedangkan penelitian oleh (Suganda et.al., 2014) menunjukkan bahwa semakin lama waktu tinggal air limbah di dalam reaktor, maka semakin besar pula efisiensi pengolahan pada industri tahu dan tempe.

Media sarang tawon juga mampu menghilangkan beberapa parameter polutan dari limbah rumah sakit dengan efisiensi penurunan COD 87,0 - 98,6 \%; BOD 53,4 - 99,3\%; Total padatan tersuspensi (TSS) 80,0 - 97,8\%; ammonia 93,75 - 98,2 \% ; dan deterjen (MBAS) 95,8 - 99,7\% (Said ${ }^{\text {a }}, 2001$ ). Sedangkan untuk limbah industri tekstil dengan kondisi waktu tinggal 1-3 hari memiliki efisiensi penghilangan BOD, COD, Zat Padat Tersuspensi dan Warna masing-masing yakni : BOD $77.84-94.88 \%$, COD $73.91-94.23 \%$, zat padat tersuspensi (SS) 93.44 - 99.84 \%, dan Warna 76.36 - 88.96 Pt-Co (Said ${ }^{\mathrm{b}}, 2001$ ).

Selain menggunakan sarang tawon, cara lainnya adalah dengan proses lumpur aktif yang diisi dengan media bio-ball (Filliazati, 2013 ; Amri dan Wesen, 2015 ; Aufa, 2015). Proses pengolahan sangat tergantung pada waktu tinggal air dalam reaktor, dimana semakin besar beban organik yang masuk kedalam bioreactor maka efisiensi penyisihannya semakin kecil. Dengan beban BOD $0,3-1,0 \mathrm{~kg} \mathrm{BOD} / \mathrm{m}^{3}$.hari efisiensi penyisihan BOD berkisar antara 80-85\% (Said dan Utomo, 2007).

Berdasarkan pada penelitian yang terdahulu menunjukan bahwa pengolahan secara anaerob dengan menggunakan media tercelup sarang tawon mampu menurunkan kadar COD, BOD, TSS, dan MBAS. Maka metode tersebut dapat digunakan untuk mengolah limbah laboratorium yang memiliki karakteristik kandungan senyawa organik yang cukup tinggi.

Selain itu, pengolahan limbah juga dapat menggunakan teknik filtrasi menggunakan berbagai macam media. Seperti kombinasi pasir-arang aktif yang mampu menurunkan kadar COD, TSS dan Warna (Setyobudiarso dan Yuwono, 2014). Lalu teknik biofiltrasi aerobik aliran downflow menggunakan sistem intermiteen dengan menggunakan media kerikil yang mampu menyisihkan BOD, COD dan TSS berturutturut 94,83\%, 92,95\% dab 95\% (Zahra dan Purwanti, 2015).

Pada penelitian ini akan diuji efektifitas dan efisiensi pengolahan limbah cair laboratorium dengan menggunakan teknik aerob-anaerob dimana pada sistem anaerob menggunakan media PVC sarang tawon dan teknik aerob menggunakan multi layer filtration yang terdiri atas batu, kerikil, ijuk, arang aktif, dan pasir. Parameter yang diuji adalah $\mathrm{pH}$, ammonia, kekeruhan, minyak lemak, COD, surfaktan dan Total Suspended Solid. Hasil pengujian akan dianalisa untuk diketahui seberapa efektif dan efisien metode pengolahan yang digunakan. Lebih lanjut hasil penelitian ini digunakan sebagai bahan evaluasi untuk meningkatkan kinerja proses pengolahan.

\section{METODE \\ Alat dan Bahan}

Peralatan yang digunakan antara lain Satu set Instalasi Pengolahan Air Limbah yang terdiri dari bak anaerob yang berisikan media sarang tawon dengan panjang $178 \mathrm{~cm}$, lebar $120 \mathrm{~cm}$ dan ke dalaman $90 \mathrm{~cm}$. Bak Filtrasi dengan panjang $60 \mathrm{~cm}$ dan lebar $60 \mathrm{~cm}$ dengan ketebalan $90 \mathrm{~cm}$ terdiri atas batu kali - ijuk - batu kerikil - ijuk-arangaktif - ijuk - batu kerikil - ijuk. Alat uji yang digunakan adalah Neraca Analitik (Shimadzu), Turbidimeter (Hach TL2350), Oven Listrik (Memmert), Waterbath (Memmert), Spektrofotometer DR 3900 dan seperangkat pompa vakum. Bahan kimia untuk melakukan pengujian meliputi reagent COD Kit (Hach), Nessler Reagent Kit (Hach), Air Demineralisasi, Kertas Saring (Whatman) 


\section{Metodologi}

Penelitian dilakukan pada bulan September-Oktober tahun 2020 berlokasi di Instalasi Pengolahan Air Limbah dan Laboratorium Penguji Baristand Industri Bandar Lampung. Air limbah dari seluruh laboratorium yang ada dikumpulkan dalam bak penampungan awal, lalu dialirkan ke dalam bak anerob 1, lalu masuk ke bak filtrasi. Sampel limbah diambil pada titik awal (inlet), lalu setelah bak anaerob (Biofilter1) dan setelah bak filtrasi (Biofilter 2) seperti yang terlihat pada Gambar 1.

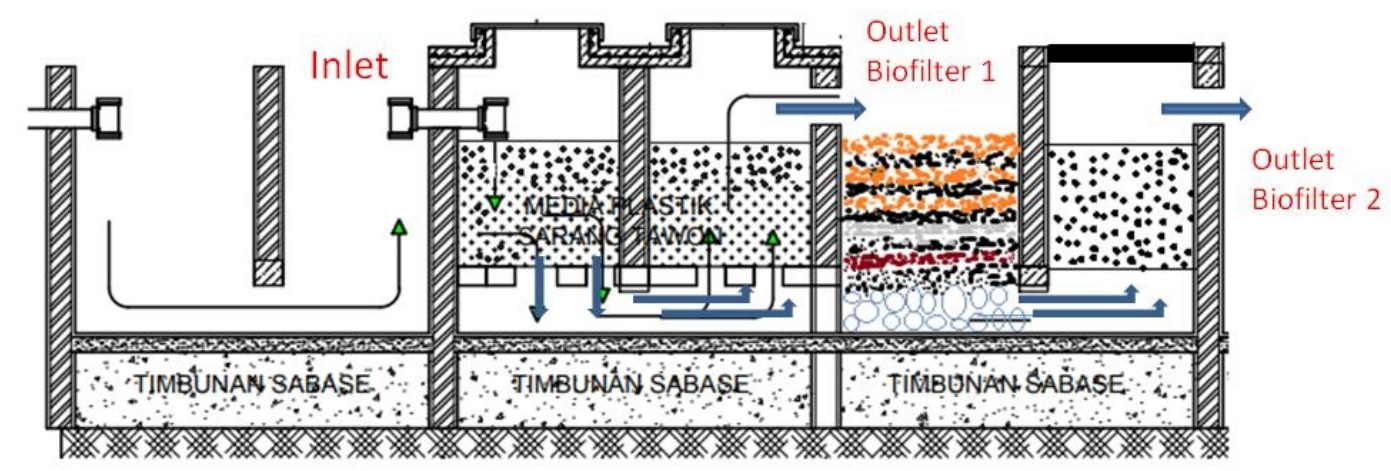

Gambar 1. Desain IPAL Sarang Tawon dan Titik Pengambilan Sampel

Masing-masing sampel dilakukan pengujian nilai $\mathrm{pH}$, ammonia, Minyak dan Lemak, Kekeruhan, COD, Surfaktan sebagai MBAS dan TSS. Lalu dilakukan pengolahan data untuk melihat kinerja IPAL.

\section{HASIL DAN PEMBAHASAN}

Instalasi pengolahan air limbah secara aerob-anaerob menggunakan media sarang tawon untuk proses pengolahan secara anaerob, sedangkan pengolahan aerob dilakukan dengan penambahan udara melalui aerator. Media sarang tawon terdiri dari plastik PVC yang dibentuk menjadi seperti sarang tawon sehingga mikroorganisme dapat tumbuh dan menempel di sarang tawon tersebut. Air limbah yang memiliki kandungan zat organik tinggi selanjutnya akan berinteraksi dengan media tersebut untuk didekomposisi secara anaerob menjadi senyawa metan yang dilepaskan ke udara. Proses kedua adalah filtrasi menggunakan sistem multi layer filtration yang terdiri atas batu, kerikil, arang aktif, batu koral, ijuk dengan lapisan seperti yang terlihat pada Gambar 1. Selanjutnya dilakukan proses anaerob kembali di media sarang tawon yang kedua.

Pada penelitian ini akan diuji kinerja sarang tawon dan media filtrasi yang telah dipasang, untuk mengukur kinerjanya maka titik sampel yang diambil adalah pada sisi inlet, outlet biofilter 1 dan outlet biofilter 2. Proses pemantauan dilakukan selama 5 hari dari hari senin hingga hari jumat. Hal ini untuk mengetahui performa IPAL selama hari kerja, apakah sudah mampu menghasilkan outlet yang stabil.

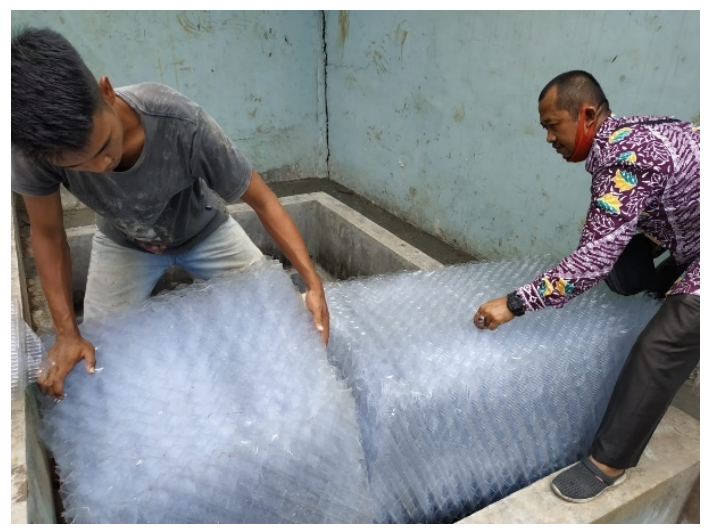

Gambar 2. Proses Pemasangan Media Sarang Tawon

Air limbah yang diolah pada IPAL berasal dari buangan wastafel laboratorium kimia, mikrobiologi dan juga kalibrasi. Karakteristik air limbah yang diolah dipengaruhi oleh jenis pengujian yang dilakukan, 
namun secara umum berasal dari air sisa cucian peralatan gelas dan juga sisa sampel. Nilai $\mathrm{pH}$ menjadi patokan awal terkait dengan kondisi air buangan. Berdasarkan pada Gambar 3, dapat dilihat bahwa pada bak inlet nilai $\mathrm{pH}$ sangat fluktuatif dari mulai 6,6 pada hari pertama, lalu sempat naik dan kembali turun drastis mencapai 5,6 pada hari ke 5. Hal ini menunjukkan bahwa kondisi air buangan yang masuk pada bak awal sangat beragam.

Setelah dilakukan pengolahan di bak biofiltrasi 1 dapat dilihat bahwa nilai $\mathrm{pH}$ sudah mulai stabil diantara 6,6 hingga 6,8. Selanjutnya setelah diolah pada bak biofiltrasi 2 nilai $\mathrm{pH}$ nya menjadi stabil antara 7,1 hingga 7,8. Hasil ini berkorelasi dengan penelitian yang dilakukan (Busyairi et al, 2020) yang menunjukan bahwa penggunaan biofilter mampu mengembalikan $\mathrm{pH}$ air limbah menjadi netral.

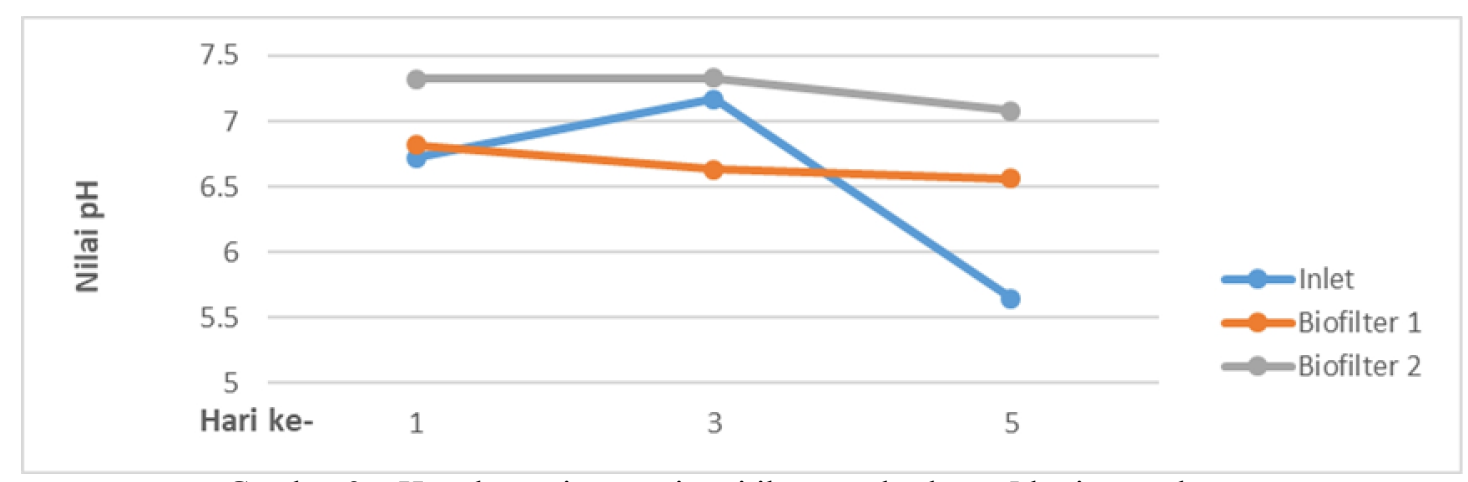

Gambar 3. pH pada masing-masing titik sampel selama 5 hari pengukuran

Ammonia berasal dari proses dekomposisi senyawa organik yang memiliki kandungan Nitrogen. Setelah terbentuksenyawa ammonia, kandungannya dapat dikurangi dengan melakukan proses aerasi sehingga ammonia akan berkurang karena menguap ke udara. Pada proses dengan menggunakan media sarang tawon terjadi proses anaerob yang merubah senyawa nitrogen menjadi ammonia.

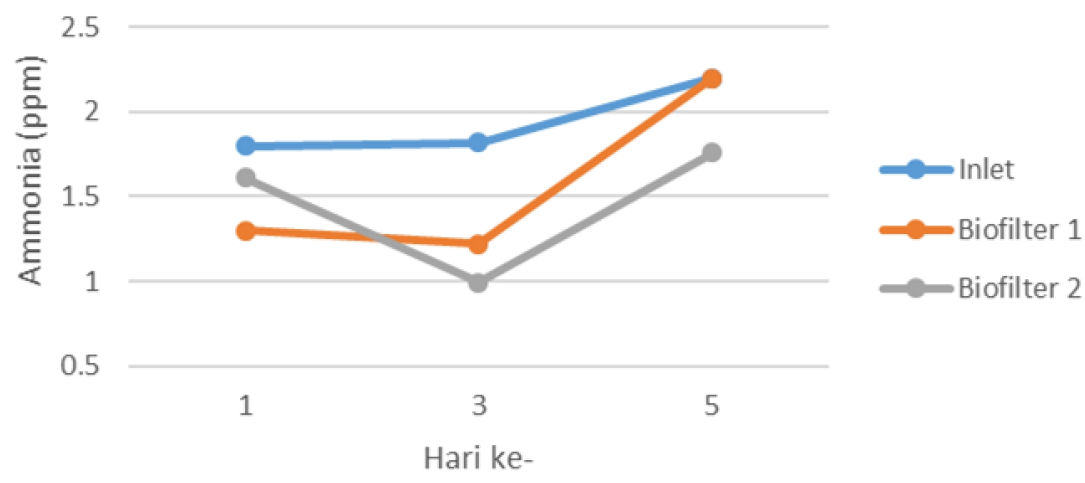

Gambar 4. Kadar Ammonia pada masing-masing titik sampling selama 5 hari pengukuran

Pada hasil pemantauan kinerja sarang tawon dan juga bak filtrasi dapat dilihat bahwa pada bak inlet kandungan ammonia stabil antara 1,8 hingga $2,2 \mathrm{mg} / \mathrm{L}$, setelah proses filtrasi mulai terjadi fluktuasi dari mulai 1,3 hingga 2,2 mg/L. Sedangkan setelah terjadi filtrasi kandungan ammonia naik turun dari 1,6 turun ke 1 dan naik kembali menjadi 1,7. Meskipun mengalami penurunan, dapat secara rata-rata hanya mengurangi kadar ammonia sebesar 25\%. Data yang dihasilkan menunjukkan bahwa proses sarang tawon dan filtrasi belum efektif untuk menurunkan kadar ammonia, sehingga perlu dilakukan proses lanjutan untuk menurunkan kadarnya. Beberapa hal yang bisa dilakukan seperti melakukan proses aerasi atau menambah waktu tinggal di bak biofiltrasi.

Bak aerob yang berisikan media sarang tawon mampu menurunkan kandungan minyak lemak dari air limbah yang masuk, hal tersebut dilihat dari Gambar 5. Pada grafik Gambar 5 dapat dilihat bahwa kandungan minyak lemak pada bak inlet berkisar antara 2,2 hingga $1,3 \mathrm{mg} / \mathrm{L}$, setelah diolah pada bak biofiltrasi 1 yang berisikan media sarang tawon kandungan minyak lemak turun menjadi antara 1,1 hingga $0,9 \mathrm{mg} / \mathrm{L}$. Setelah diolah pada bakbiofiltrasi 2 kembali turun menjadi antara 0,7 hingga $0,5 \mathrm{mg} / \mathrm{L}$. Secara keseluruhan bila 
dirata-ratakan maka bak filtrasi mampu menurunkan kandungan Minyak dan Lemak sebesar $63 \%$. Berdasarkan data tersebut dapat dilihat bahwa bak sarang tawon cukup efektif untuk memisahkan kandungan minyak dalam air limbah.

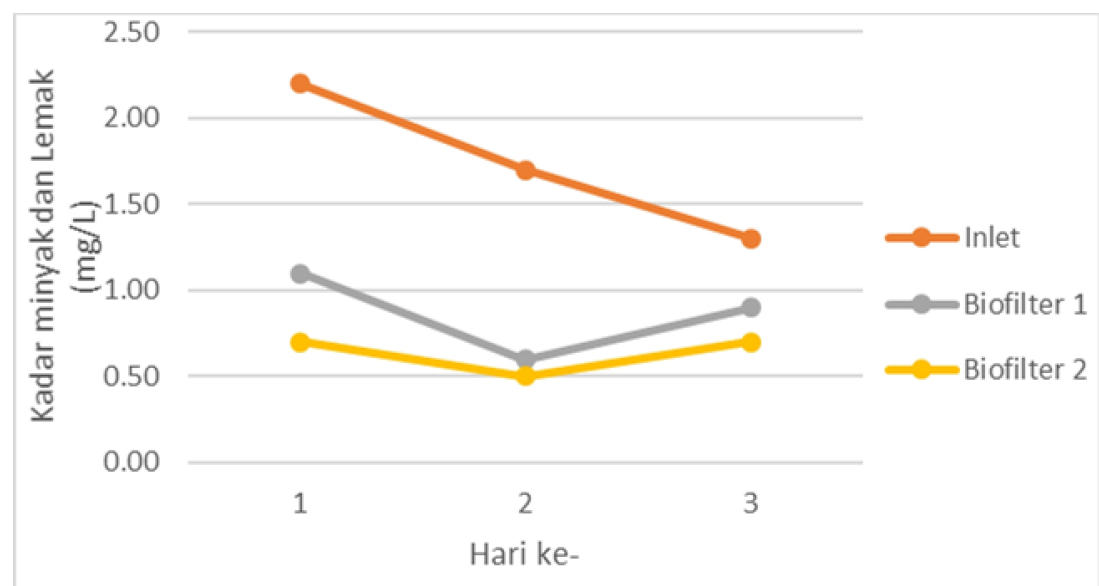

Gambar 5. Kadar Minyak dan Lemak pada masing-masing titik sampling selama 5 hari pengukuran

Penurunan kandungan minyak lemak dapat terjadi karena pada proses biofiltrasi menggunakan aliran naik turun, sehingga minyak dan lemak yang memiliki berat jenis lebih ringan dari air akan terpisahkan dan berkumpul dibagian atas permukaan.

Nilai kekeruhan dapat menjadi indikator awal yang paling mudah untuk melihat kualitas air, bila terlihat keruh dapat ditarik asumsi bahwa air banyak mengandung senyawa tidak terlarut yang berasal dari berbagai macam sumber. Hasil pemantauan nilai kekeruhan dapat dilihat pada Gambar 6 .

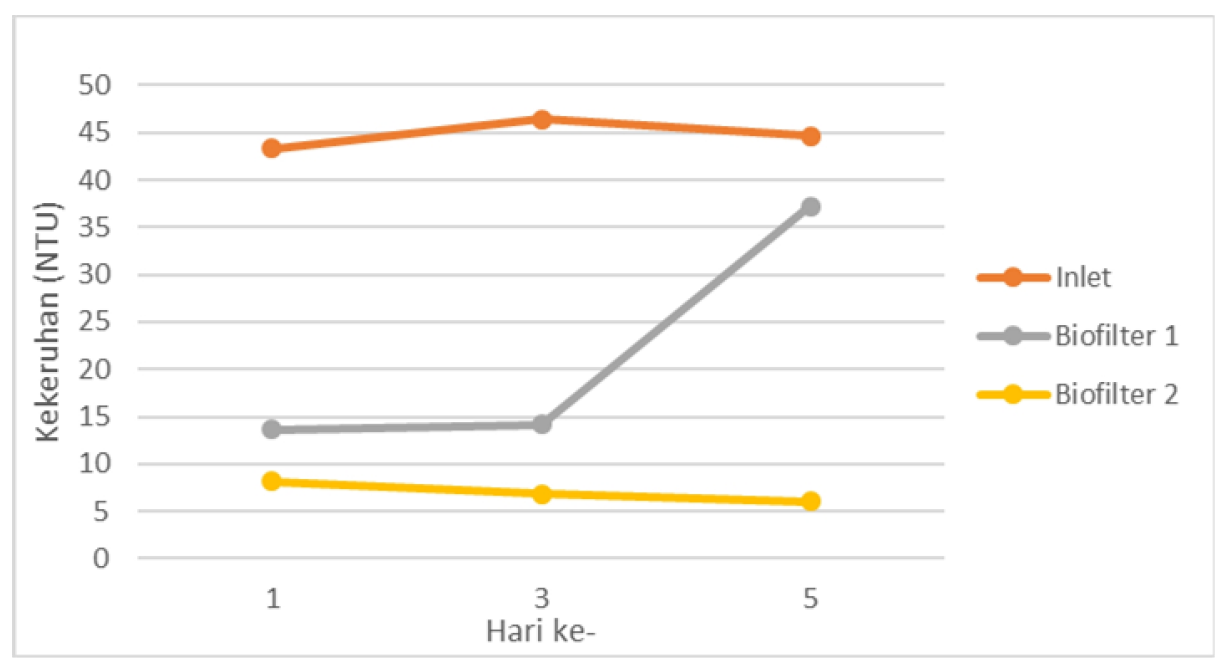

Gambar 6. Nilai Kekeruhan Pada Masing-Masing Titik Selama 5 hari pengukuran

Pada bak inlet terlihat bahwa kekeruhan air stabil diantara 43 hingga 46 NTU, setelah dilakukan pengolahan pada biofilter 1 nilainya turun menjadi 13,6 NTU dan cukup stabil hingga hari ke 3, namun pada hari ke-5 nilai kekeruhan naik drastis hingga 37 NTU. Sedangkan setelah proses pada bak biofiltrasi 2nilai NTU turun secara signifikan menjadi di antara 8 hingga 6 NTU. Secara keselurahan sistem pengolahan mampu menurunkan nilai kekeruhan sebesar $84,33 \%$. Nilai kekeruhan dapat turun drastis karena pada bak biofiltrasi kedua terdiri dari berbagai lapisan yang mampu menahan zat tidak terlarut sehingga padatan tersebut tertahan dan menghasilkan air yang lebih jernih. Hal ini sejalan dengan penelitian yang dilakukan oleh (Sulastri dan Nurhayati,2014) yang mampu menurunkan nilai kekeruhan hingga 89,41\% dengan menggunakan reactor filtrasi yang berisikan ijuk, koral, pasir dan arang aktif.

Kadar COD dipengaruhi oleh kandungan senyawa organik dan juga senyawa anorganik yang berasal dari buangan air limbah. Proses anaerob pada sarang tawon bertujuan untuk menurunkan kandungan senyawa 
organik dengan cara mendekomposisikannya hingga menjadi gas metan yang selanjutnya akan dibuang keudara. Pada bak inlet terlihat nilai COD mengalami fluktuasi dari $476 \mathrm{mg} / \mathrm{L}$ lalu turun ke $369 \mathrm{mg} / \mathrm{L}$ dan kembali naik menjadi $434 \mathrm{mg} / \mathrm{L}$. Hal tersebut menunjukkan bahwa air limbah yang masuk memiliki karakteristik yang berbeda.

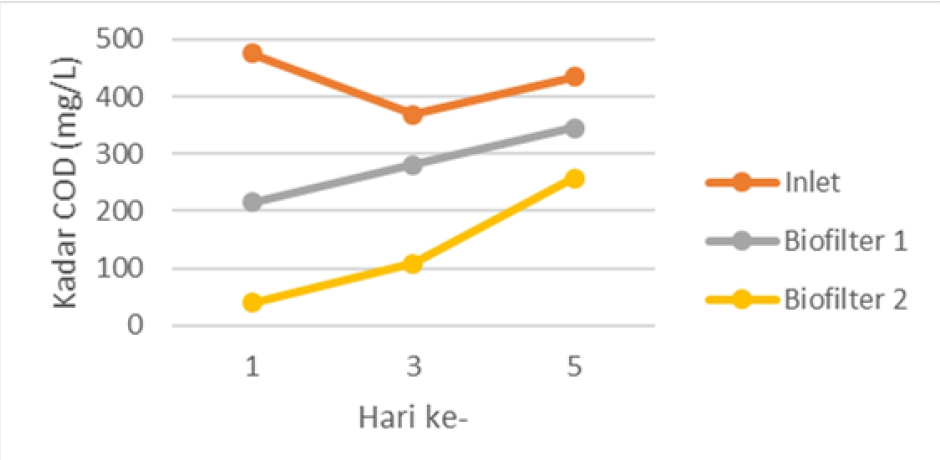

Gambar 7. Kadar COD pada masing-masing titik selama 5 hari pengukuran

Air limbah yang telah diolah pada bak biofiltrasi 1 memiliki kadar COD yang lebih kecil dibandingkan dengan inlet. Begitu juga setelah dilakukan pengolahan pada bak filtrasi 2, kadar COD menurun menjadi $40 \mathrm{mg} / \mathrm{L}$ namun mengalami kenaikan secara signifikan menjadi $247 \mathrm{mg} / \mathrm{L}$ pada hari ke-5. Secara keseluruhan, proses pengolahan yang terjadi mampu menurunkan kadar COD sebesar $68,33 \%$.

Dari data yang dihasilkan dapat dilihat bahwa meskipun pada hari pertama kandungan COD di bak biofiltrasi 2 kecil namun pada hari ke-3 dan ke-5 mengalami kenaikan yang cukup signifikan, hal tersebut dapat terjadi karena pada saat hari kerja beban air limbah yang diolah meningkat, sehingga waktu tinggal pada masing-masing bak menjadi berkurang. Berdasarkan data tersebut maka perlu dilakukan modifikasi lebih lanjut pada bak biofiltrasi 1 dan 2 agar proses pengolahan menjadi lebih optimal.

Salah satu kandungan dalam air cucian wastafel adalah deterjen/surfaktan (ditetapkan sebagai MBAS) yang digunakan untuk mencuci peralatan gelas. Kadar MBAS pada bak inlet sebesar $0,72 \mathrm{mg} / \mathrm{L}$ pada hari pertama menjadi $0,87 \mathrm{mg} / \mathrm{kg}$ pada hari ke lima. Kadar MBAS menurun setelah melalui bak biofiltrasi 1 menjadi berkisar antara 0,38 sampai $0,45 \mathrm{mg} / \mathrm{L}$. Setelah melewati bak biofiltrasi 2 kandungannya kembali turun menjadi antara 0,23 hingga $0,32 \mathrm{mg} / \mathrm{L}$. Hal tersebut dapat dilihat pada Gambar 8. Bila dirata-ratakan, penurunan kandungan MBAS sebesar $61 \%$. Kandungan MBAS yang semakin menurun menunjukkan bahwa proses anaerob mampu mendegradasikan surfaktan yang terkandung dalam air limbah. Hal ini sejalan dengan penelitian yang dilakukan (Sopiah dan Chaerunisah, 2006) bahwa media sarang tawon mampu mendegradasi surfaktan linaralkilbenzenasulfonat (LAS) pada limbah deterjen dengan menggunakan media sarang tawon.

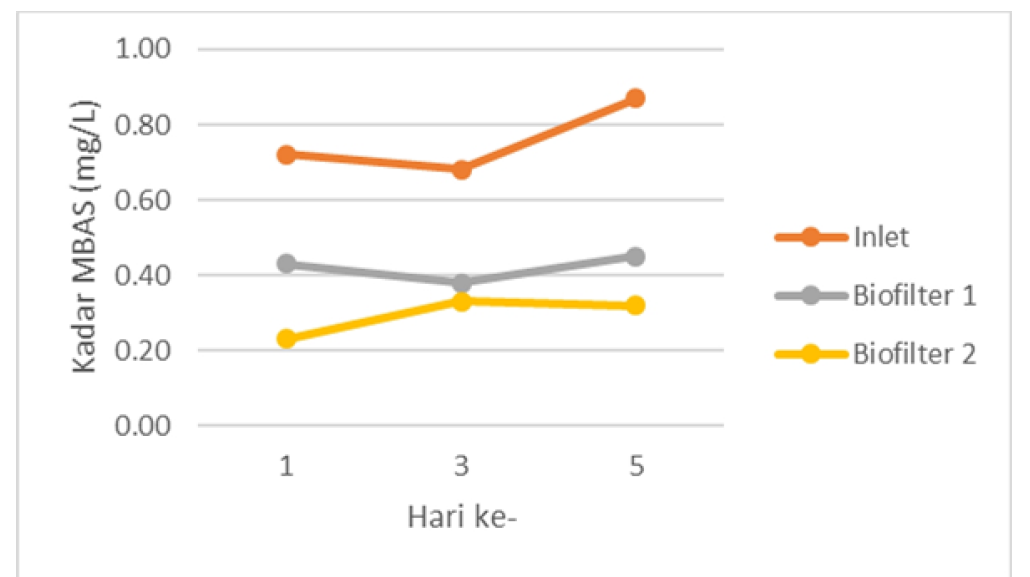

Gambar 8. Kadar MBAS pada masing-masing titik selama 5 hari pengukuran

Kadar TSS atau juga padatan tidak terlarut menunjukkan banyaknya kotoran yang ada di dalam air. Semakin tinggi kandungannya maka kualitas air semakin menurun karena dapat mengakibatkan warna air yang menjadi semakin gelap. Kandungan TSS sangat terkorelasi dengan nilai kekeruhan, semakin tinggi TSS 
maka kekeruhan biasanya akan semakin tinggi. Hasil pemantauan kandungan TSS dapat dilihat pada Gambar 9.

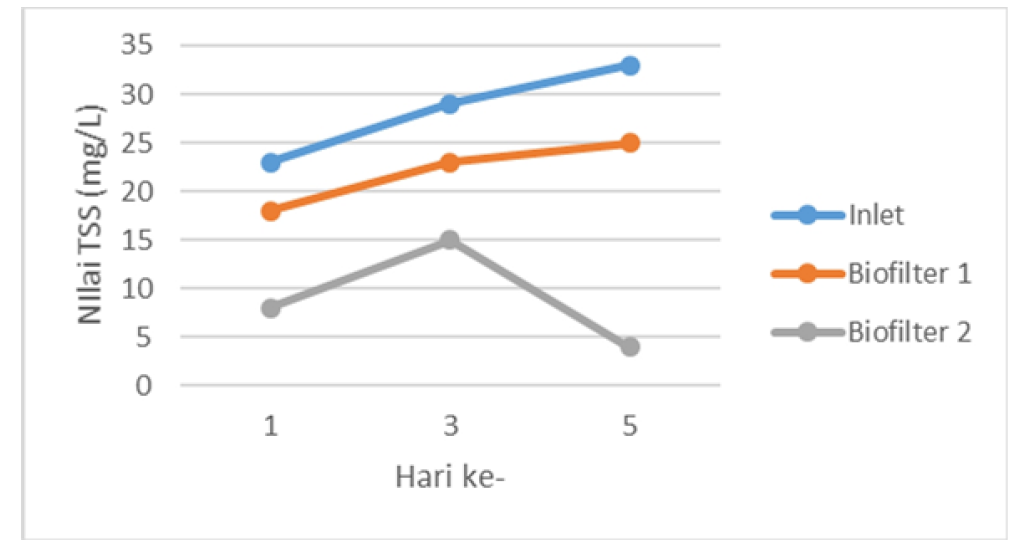

Gambar 9. Nilai TSS pada masing-masing titik selama 5 hari pengukuran

Pada penelitian ini dapat dilihat bahwa kandungan TSS pada bak inlet semakin meningkat dari 23 $\mathrm{mg} / \mathrm{L}$ pada hari pertama menjadi $33 \mathrm{mg} / \mathrm{L}$ pada hari ke 5 . Setelah melalui bak biofilrasi 1 nilainya menjadi turun menjadi berkisar antara 18 hingga $23 \mathrm{mg} / \mathrm{L}$. Selanjutnya air diolah pada bak biofiltrasi 2 dankandungannya semakin menurun, pada hari pertama sebesar $8 \mathrm{mg} / \mathrm{L}$ menjadi $4 \mathrm{mg} / \mathrm{L}$ pada hari ke-5. Secara keseluruhan, proses pengolahan air limbah mampu menurunkan nilai TSS sebesar $68 \%$. Hasil tersebut menunjukan bahwa bak biofiltrasi 2 yang terdiri dari beberapa lapis media telah bekerja secara optimal menyaring padatan yang tak terlarut di dalam air. Hasil ini sejalan dengan hasil penelitian(Singga dan Dukabain, 2019) yang mampu menurunkan kandungan TSS sebesar 89,2\% dengan menggunakan biofilter.

\section{KESIMPULAN}

Instalasi Pengolahan Air Limbah dengan sistem aerob-anaerob menggunakan media biofiltrasi sarang tawon dan Multi Layer Filtration (MLF) yang terdiri dari batu, kerikil, arang aktif, ijuk, dan pasir telah berhasil dibuat. Selanjutnya dilakukan uji kinerja dengan memantau nilai $\mathrm{pH}$, kandungan ammonia, Kekeruhan, COD, TSS, Minyak Lemak dan Surfaktan sebagai MBAS pada hari Ke-1, 3 dan 5. Hasil pengujian menunjukkan bahwa kombinasi media sarang tawon dan MLF telah efektif dan efesien untuk menurunkan nilai kekeruhan sebesar 84,3\%, TSS 68,2\%, COD 68,33\%, Minyak Lemak 63,46\% MBAS $61,23 \%$ dan ammonia sebesar 25\%. Selain itu, IPAL mampu mengembalikan pH air menjadi netral.

\section{UCAPAN TERIMA KASIH}

Terima Kasih disampaikan kepada Kepala Baristand Industri Bandar Lampung, Ibu Prima Yudha Hayati, yang telah mendukung pelaksanaan kegiatan penelitian ini. Kepada para analis di laboratorium, Bapak Herman, Bapak Buhari, Mba Fitri yang telah membantu proses pengujian.

\section{REFERENSI}

Aufa, I, 2015. Analisis Penurunan COD pada Air Limbah Non Toksik Rumah Sakit X Menggunakan Biofilter Aerobik. Tugas Akhir. Institut Teknologi Sepuluh Nopember.

Amri, K., \& Wesen, P. 2015. Pengolahan air limbah domestik menggunakan biofilter anaerob bermedia plastik (bioball). Jurnal Ilmiah Teknik Lingkungan, 7(2), 55-56.

Busyairi, M., Adriyanti, N., Kahar, A., Nurcahya, D., \&Sariyadi, S., 2020. EfektivitasPengolahan Air LimbahDomestik Grey Water Dengan Proses Biofilter Anaerob dan Biofilter Aerob (StudiKasus: IPAL INBIS Permata Bunda, Bontang). JurnalSerambi Engineering, 5(4), 1306-1312

Filliazati, M. 2013. Pengolahan Limbah cair Domestik Dengan Biofilter Aerob Menggunakan Media Bioball dan tanaman Kiambang. Desertasi, Universitas Tanjungpura.

Herlambang, A. 2001. Pengaruh Pemakaian Biofilter Struktur Sarang Tawon Pada Pengolah Limbah Organik Sistem Kombinasi Anaerob-Aerob (Studi Kasus: Limbah Tahu Dan Tempe). Jurnal Teknologi Lingkungan, 2(1), 28-36. doi:https://doi.org/10.29122/jtl.v2i1.195 
Said $^{a}$, N. I. 2001. Pengolahan Air Limbah Industri Kecil Tekstil Dengan Proses Biofilter Anaerob-Aerob Tercelup Menggunakan Media Plastik Sarang Tawon. Jurnal Teknologi Lingkungan, 2(2), 124-135.

Said b, N. I. 2001. Pengolahan Air Limbah Rumah Sakit Dengan Proses Biologis Biakan Melekat Menggunakan Media Palstik Sarang TAWON. Jurnal Teknologi Lingkungan, 2(3), 223-240. doi:http://dx.doi.org/10.29122/jtl.v2i3.217

Said, N. I. 2005. Penggunaan Media Serat Plastik pada Proses Biofilter Tercelup untuk Pengolahan Air Limbah Rumah Tangga Non Toilet. Jurnal Air Indonesia, 1(2), 143-156. doi:https://doi.org/10.29122/jai.v1i2.2342

Said, N. I. 2009. Uji Kinerja Pengolahan Air Siap Minum Dengan Proses Biofiltrasi, Ultrafiltrasi Dan Reverse Osmosis (RO) Dengan Air Baku Air Sungai. Jurnal AIr Indonesia, 5(2), 144-161. doi:http://dx.doi.org/10.29122/jai.v5i2.2444

Said, N. I., \& Utomo, K. 2007. Pengolahan Air Limbah Domestik Dengan Proses Lumpur Aktif Yang Diisi Dengan Media Bioball. Jurnal Air Indonesia, 3(2), 160-174. doi:https://doi.org/10.29122/jai.v3i2.2337

Sali, G. P., Suprabawati, A., \& Purwanto, Y. 2018. Efektivitas Teknik Biofiltrasi Dengan Media Sarang Tawon Terhadap Penurunan Kadar Nitrogen Total Limbah Cair. Jurnal Presipitasi : Media Komunikasi dan Pengembangan Teknik Lingkungan, 15(1), 1-6.

Setyobudiarso, H., \& Yuwono, E. 2014. Rancang bangun alat penjernih air limbah cair laundry dengan menggunakan media penyaring kombinasi pasir-arang aktif. Jurnal Neutrino: Jurnal Fisika dan Aplikasinya, 84-90. doi:https://doi.org/ 10.18860/neu.v0i0.2587

Singga, S., \&Dukabain, O. M. 2019. Kombinasi Metode Anaerob dan Aerob Pada Septiktank untuk Menurunkan Kadar BOD, TSS dan Coliform Pada Limbah Cair RumahTangga. Oehònis: The Journal of Environmental Health Research, 3(1), 180-184.

Sopiah R. N. dan Chaerunisah, 2006. Laju Degradasi Surfaktan Linear Alkil benzena Sulfonat (LAS) pada Limbah Deterjen secara Anaerob pada Reaktor Lekat Diam Bermedia Sarang Tawon. Jurnal. Tek. Lingkungan. P3TL-BPPT. 7. (3): 243-250

Sulastri, S., \&Nurhayati, I., 2014. Pengaruh Media Filtrasi Arang Aktif Terhadap Kekeruhan, Warnadan TDS Pada Air Telaga Di DesaBalongpanggang. Jurnal Teknik WAKTU, 12(1), 43-47.

Suganda, R., Sutrisno, E., \& Wardana, I. W, 2014. Penurunan Konsentrasi Amonia, Nitrat, Nitrit Dan Cod Dalam Limbah Cair Tahu Dengan Menggunakan Biofilm - Kolam (Pond) Media Pipa PVC Sarang Tawon Dan Tempurung Kelapa Disertasi Penambahan Ecotru. Jurnal Teknik Lingkungan, 3(4), 1-8.

Zahra, L. Z., \& Purwanti, I. F., 2015. Pengolahan Limbah Rumah Makan Dengan Proses Biofilter Aerobik. Jurnal Teknik Its, 4(1), 35-39. 